\title{
Research and application of food safety Pre-warning model based on AHP and time series Association
}

\author{
Shilong Guo ${ }^{1, a}$, Yong Wang ${ }^{2, b}$ \\ ${ }^{1}$ School of Computer,Guangdong University of Technology, Guangzhou, 51006, China \\ ${ }^{2}$ School of Computer,Guangdong University of Technology, Guangzhou, 51006, China \\ aemail: 736921396@qq.com, bemail: 13928887919@126.com
}

Keywords: analytic hierarchy process;Pre-warning system;Temporal association;food safety

\begin{abstract}
Establishing food safety warning system hierarchy based on AHP,through the HACCP system and the time sequence related knowledge, the food safety critical control index is obtained,combined with the nine level scale method, the five point scale scale to establish the judgment matrix and calculate the food safety control index weight value,and construct food safety warning model,monitoring of food safety state in Real-time,combinate the time series can minimize the risk.in a time stamp.A food safety early warning model was established for vegetable processing in a prefecture level city and validate the validity of the early warning model.
\end{abstract}

\section{Introduction}

Food safety early warning system plays an important role in the national food safety strategy. In the "food safety information early warning model based on association rules mining", Gu Xiaolin proposed the food safety information based on association rules algorithm[1]. Zhang Debin proposed based on the BP neural network algorithm training experience data samples to establish a food safety model to predict the risk of food safety[2]. Based on the analytic hierarchy process (AHP) and the time series correlation analysis, this paper establishes a food safety early warning model, with practical and systematic characteristics, qualitative and quantitative analysis of the key factors in the food safety control chain, So as to establish an effective food safety warning model.

\section{Related Algorithm}

Based on AHP to establish the concept of early warning model. Constructing the hierarchical structure model of the system.Structure judgment matrix (positive reciprocal matrix), In this paper, we use the nine scale method of T.L.Saaty [3] [4]to $n$ factors $X=\left\{X_{1}, X_{2}, \ldots, X_{n}\right\}$, base on the importance of each element to construct the judgment matrix.

Determination of factor weight and consistency check. In this paper, the root method is used to solve the characteristic vector that is the weight value $\mathrm{W}_{\mathrm{i}}$. The solution procedure is as follows:

(1) Get sum of the judgment matrix A by line: $s_{i}=\sum a_{i j}(i, j=1,2, \ldots, n)$, then the judgment matrix is obtained $B=\left(B_{i j}\right)_{n \times n}$ :

$$
B_{i j}=\left\{\begin{array}{c}
{\left[\left(s_{i}-s_{j}\right) /\left(s_{\text {max }}-s_{\min }\right)\right] \times\left(a_{m}-1\right)+1,\left(r_{i} \geqslant r_{j}\right)} \\
\left.\left\{\left(s_{j}-s_{i}\right) /\left(s_{\text {max }}-s_{\min }\right)\right] \times\left(a_{m}-1\right)+1\right\}^{-1},\left(r_{i}<r_{j}\right)
\end{array}\right.
$$

Get the line integral according to the B matrix: $N_{i}=\prod b_{i j}(i, j=1,2, \ldots, n)$, as follows : 


$$
N=\left[\begin{array}{c}
N_{1} \\
N_{2} \\
\vdots \\
N_{n}
\end{array}\right]=\left[\begin{array}{c}
b_{11} \times b_{12} \times \cdots \times b_{1 n} \\
b_{21} \times b_{22} \times \cdots \times b_{2 n} \\
\vdots \\
b_{n 1} \times b_{n 2} \times \cdots \times b_{n n}
\end{array}\right]
$$

(2) $\mathrm{N}$ root mean square of $\mathrm{N}_{\mathrm{i}}$ :

$$
\bar{N}_{i}=\sqrt[n]{N_{i}}, \bar{N}=\left[\bar{N}_{i}\right], i=1 \cdots n
$$

(3) Normalized to obtain the weight value :

$$
w_{i}=\frac{\bar{N}_{i}}{\sum_{i} \bar{N}_{i}}, i=1 \cdots n, \sum w_{i}=1
$$

(4) Maximum eigenvalue :

$$
\lambda_{\max }=\sum_{i=1}^{n} w_{i} S /
$$

(5) Consistency check:

To check whether the weight of the index is reasonable, need to test the consistency of the judgment matrix :

$$
C . R .=\frac{C . I .}{R . I .} \quad \text { (6) } \quad \text { C.I. }=\frac{\lambda_{\mathrm{MAX}}-n}{n-1}
$$

Calculation of sufficient data, the value of $R$.I . shown as table1.

Tab. 1. Random consistency index of $\mathrm{n}$ order matrix

\begin{tabular}{cccccc}
\hline Order number $\mathrm{n}$ & 1 & 2 & 3 & 4 & 5 \\
R.I. & 0.00 & 0.00 & 0.58 & 0.90 & 1.12 \\
Order number $\mathrm{n}$ & 6 & 7 & 8 & 9 & 10 \\
R.I. & 1.24 & 1.32 & 1.41 & 1.45 & 1.49
\end{tabular}

If $C . R .<0.10$, the consistency of judgment matrix is considered, else the consistency of judgment matrix is not considered, should be re adjusted estimates, until the satisfaction of the consistency test.

Mining sequential association rules using Apriori algorithm

(1) Frequent sets with time series attributes are used to mining the support degree than the minimum support degree by using Apriori algorithm[5].

(2) List the regular pattern of the frequent sets, and find out the time sequence association rules which satisfy the minimum support degree.

(3) Find the time sequence association rules which satisfy the minimum confidence.

\section{Example and analysis of food safety Pre-warning model}

Obtain the key control factors of vegetable processing products. It can be concluded that the key control indexes in the control chain of vegetable processing products are shown in table 2[6]. 
Tab. 2. Key control index of vegetable processing

\begin{tabular}{|c|c|c|}
\hline Target layer & Criterion layer & Scheme layer \\
\hline \multirow{12}{*}{$\begin{array}{l}\text { Safety general situation of vegetable } \\
\text { processing products (B) }\end{array}$} & \multirow{3}{*}{$\begin{array}{l}\text { Raw material inspection } \\
\qquad\left(\mathrm{B}_{1}\right)\end{array}$} & Pesticide residue sampling pass rate $B_{11}$ \\
\hline & & Vegetable raw material output $\mathrm{B}_{12}$ \\
\hline & & $\begin{array}{l}\text { The qualified rate of the pollution of } \\
\text { vegetables } B_{13}\end{array}$ \\
\hline & \multirow{3}{*}{$\begin{array}{l}\text { Production and processing } \\
\qquad\left(\mathrm{B}_{2}\right)\end{array}$} & Qualified rate of packaging materials $B_{21}$ \\
\hline & & $\begin{array}{l}\text { Disinfection qualification rate of } \\
\text { processing machinery } B_{22}\end{array}$ \\
\hline & & Qualified rate of food additives $B_{23}$ \\
\hline & \multirow{3}{*}{ Storage $\left(B_{3}\right)$} & Storage room temperature $B_{31}$ \\
\hline & & Storage room cleaning frequency $\mathrm{B}_{32}$ \\
\hline & & Storage room humidity $\mathrm{B}_{33}$ \\
\hline & \multirow{3}{*}{ transport $\left(\mathrm{B}_{4}\right)$} & Transportation time $\mathrm{B}_{41}$ \\
\hline & & Transport tool B 42 \\
\hline & & Transportation weather $\mathrm{B}_{43}$ \\
\hline
\end{tabular}

Get data and test model. Access to May 2015 data analysis available in May to determine the general situation of the vegetable processing products safety judgment matrix $\mathrm{D}$ as follows :

$$
D=\left(\begin{array}{lll}
2 & 3 & 4 \\
4 & 5 & 3 \\
3 & 3 & 4 \\
2 & 3 & 3
\end{array}\right)
$$

And $W_{i}=(0.490,0.285,0.057,0.168)$

$$
\begin{gathered}
w_{i j}=\left(\begin{array}{lll}
0.264 & 0.591 & 0.146 \\
0.085 & 0.232 & 0.683 \\
0.195 & 0.169 & 0.630 \\
0.281 & 0.645 & 0.076
\end{array}\right) \\
D=\sum_{i=1}^{4} w_{i} \sum_{j=1}^{3}\left(D_{i j} w_{i j}\right)=\sum_{i=1}^{4} W_{i}\left(D_{i 1} w_{i 1}+D_{i 2} w_{i 2}+D_{i 3} w_{i 3}\right)=3.257
\end{gathered}
$$

It can be calculated that the vegetable processing product safety index was 3.25 in May, this is consistent with a slightly smaller food safety situation at that time.

\section{Summary and Prospect}

In this paper, AHP analysis method establishment of food security early warning model based on the theory of temporal association and hierarchy analysis is introduced the basic principle of the method, and verify the effectiveness of the prediction model, combined with temporal association knowledge can effectively control the risks, within a certain time stamp of the risk to a minimum. 


\section{Acknowledgment}

In this paper, the research was sponsored by Guangdong Province, the Ministry of education, the combination of production and research project(No. 2012B091100071).

\section{References}

[1] Gu Xiao-lin,ZHANG Da-wei,ZHANG Ke.The Information Pre-warning Model of Food Safety Based on Association Rules Mining[J].Soft Science, 2011,25(11):136-141.

[2] Zhang De-bin,XU Jia-peng,XU Jian-jun. Food safety early warning model based on monitoring data and BP neural network $[\mathrm{J}]$. Transactions of the Chinese Society of Agricultural Engineering,2010,26(1):221-226.

[3] Huang Qiu-ting, DING Yi, QIU Pei-li.Study on the Prediction of Food Safety Monitoring Based on GM(1,1) Modified Residual Error Model[J]. Modern Agricultural Science and Technology,2013,25(5):304-311.

[4] PHOTIS PAPADEMAS,THOMAS BINTSIS.Food safety management systems(FSMS)in the dairy industry:A review[J].International Journal of Dairy Technology,2010,10(63):489-503

[5] Wang Jun, LIU Wen-fen, GAO Yan.Trust Model of Cloud Computing Based on Multi-parameters Evalution[J]. Computer Science,2015,42(6A):315-320.

[6] Su Xiao-yan, Zhang Hui-jie, Li Zhi-qiang. China's grain security early warning system based on multi factor information fusion[J]. Transactions of the Chinese Society of Agricultural Engineering,2011,27(5):183-189. 